\title{
Enterprise Financial Management System Analysis and Design based on ERP
}

\author{
Yumei Ding \\ School of management, Wuhan University of technology, Wuhan, 430070, China
}

Keywords: Financial Management System; Analysis and Design; ERP.

\begin{abstract}
With the rapid development of information technology and network, the modern enterprise management model is also undergoing tremendous changes, companies must adapt to the financial management of network and information technology development. Enterprise financial management system is a financial planning, control, supervise and manage the use of information systems to ensure that the company's good operating and financial standardized management, data analysis and processing it, improve financial management, and provide strong support for enterprise information management leadership and decision-making.
\end{abstract}

\section{Introduction}

As China's socialist market economy continues to develop and the overall development of the globalization of trade, the role of business management in the enterprise development is even more important, and financial management is the top priority of all business management. But most of our internal financial management system of enterprise groups is lagging behind. If the company wants to maximize the overall interests of the group, financial management is necessary to change from the past local, decentralized management shift to centralized management. Development of network technology, offers the possibility to build centralized enterprise group financial management mode.

Therefore, we use the current most popular ERP financial management system background, analysis and design one for corporate financial management information system using modern information network technology and software engineering technology.

\section{Related technical theory}

The discussed model is given as follow:

The rapid development of information technology makes the financial accounting system has undergone tremendous changes, and in the process of the information network, we have to analyze the situation related to the financial system. First, the technical framework of the financial system can be divided into three stages: Really a development process shown in Figure 1:

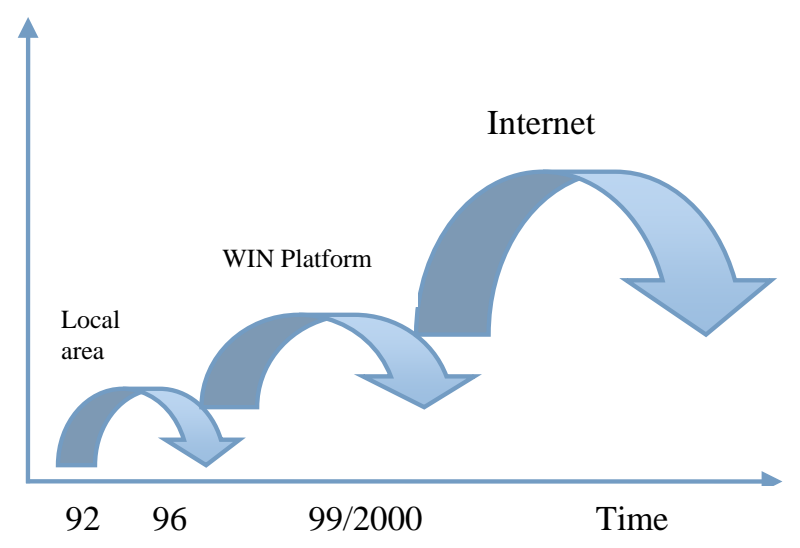

Fig. 1: Financial software technology course 
From the figure, we can see the technical framework of the financial system from the initial DOS platform to later Window platform, to the present, the financial system has been the third stage, which is the age of the Internet.

Financial management information has become an inevitable trend. Accounting information is the core of financial information. Accounting information is restructuring the traditional accounting model using modern information technology, on this basis, the establishment of information technology and the high degree of integration of the accounting discipline and full open modern accounting information systems. On the basis of information, achieving financial information is the inevitable trend.

After determining platform framework, we need to determine the architecture of software technology, computer software architecture currently include C / S and B / S architecture, we use the B/S architecture in this paper. B / S architecture (Browser / Server, Browser / Server mode), is a network structure model after the rise WEB, WEB browser is the most important application of the client software. This model unifies the client, the core of the system function to a centralized server, simplifying system development, maintenance and use. Just install the client browser, such as Netscape Navigator or Internet Explorer, server installation Oracle, Sybase, Informix, or SQL Server and other databases. Browser Web Server to interact with the database through the data.

\section{ERP Data Warehouse Technology}

In addition to providing ERP system to record, store corporate information on all aspects of information sharing capabilities, it also needs to provide leadership DSS to assist decision-making.

Early 1980s, relational database technology matures, decision support further deepen research, there has been based on the "three libraries" relational database decision support systems (database, model base, rule base) structure.

A data warehouse is object-oriented, integrated, at different times, nonvolatile to support management decision-making process of data integration.

Data warehouse system is the data extracted from operational transaction systems environment clean-up after the conversion is stored in the database. The system data is then presented to the user in a certain form.

The purpose of the use of different data warehouses and traditional transaction databases, and therefore has the following characteristics:

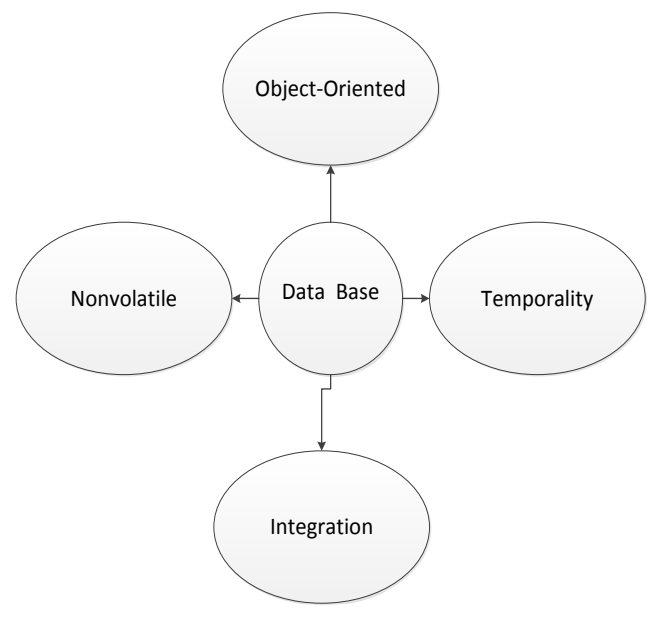

Fig. 2: Characteristics of data base for ERP

Objection: Data in the data warehouse business revolves around an object (such as sales) and other organized.

Integration: This is a data warehouse is the integration of data, because the data in the data warehouse is extracted from various application systems integration out of the data should ensure that the data is clean and determined. 
Nonvolatile: refers to the data in the data warehouse is read-only user data cannot be updated, and OLTP systems which are completely different.

Temporality: the data warehouse should increase each time a record field to record data loading time data warehouse, because the decision-making system based on the data in the data warehouse needs to analyze business a topic

Development trends of the object.

Data warehouse architecture can be shown below:

(1)Data acquisition module: used to get data from the source file and the source database, and clean, transport, loading them into the data warehouse database.

(2)Data Administrator module: used to establish, manage and access data in the data warehouse.

(3)Information Management Module: to provide the content and meaning of the information stored in the data warehouse database on the data for managers and business users.

(4)Middleware modules: a database for the data warehouse and end-user tools to link up, providing end users with data warehouse from a business point of view perspective, and to monitor and track access to the data warehouse, the improvement of the relational database system for multidimensional data analysis results.

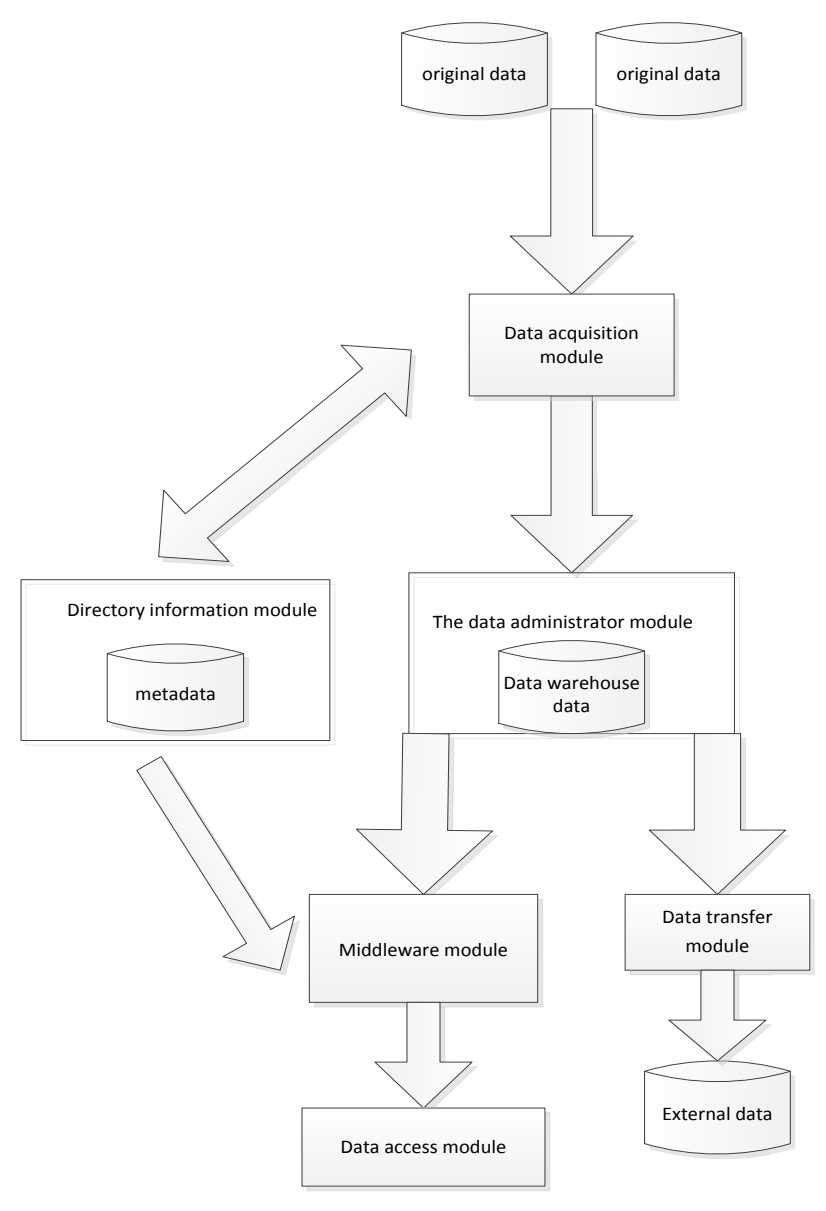

(5)Data transfer modules: data warehouse for distribution to other data warehousing and external systems

(6)Management Module: to manage the operation of the entire data warehouse system.

(7)Metadata: is data about data, including technical metadata and business metadata. Technical metadata includes information such as a data warehouse on the data source, data target, data cleaning rules and other information for warehouse design and management personnel to use when developing and maintaining a data warehouse management: business metadata enables end-users to more easily from a business perspective to understand the data in the data warehouse, including the 
corresponding business relationship between themes and technical metadata, the book details such as query and reporting information.

\section{System Design}

Enterprise financial management system should be developed along with the development of enterprises, its construction should meet the business development of the Group. In many companies in our country, the lag of financial system has led to the overall financial management cannot fully play its role, it's a question of the most prominent is the information network management is not perfect. Most companies simply use a computer to accounting, there is no information to realize the depth of excavation, and thus not conducive to management decisionmaking and management.

Therefore, companies need to develop well-designed financial information management system for the collection, processing and analysis of financial information, so that finance of companies can be systematic, information technology, holistic.

The main flow of financial information management system design is similar with most of the software design process, whole-step process as shown below:

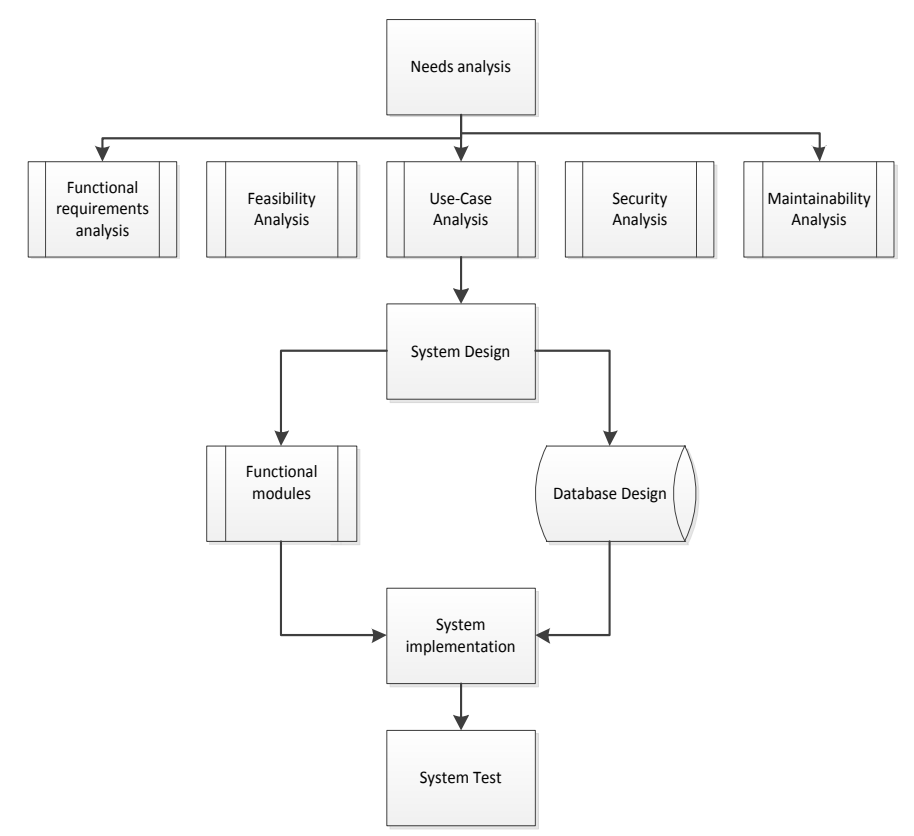

Fig.3: System design flow

Financial information management system designed to achieve can bring a new change for the development of enterprises, in the ERP system, corporate financial information management is the core financial management system, meanwhile, corporate financial management systems and other management systems are also inseparable whole, its application environment, as shown below: 


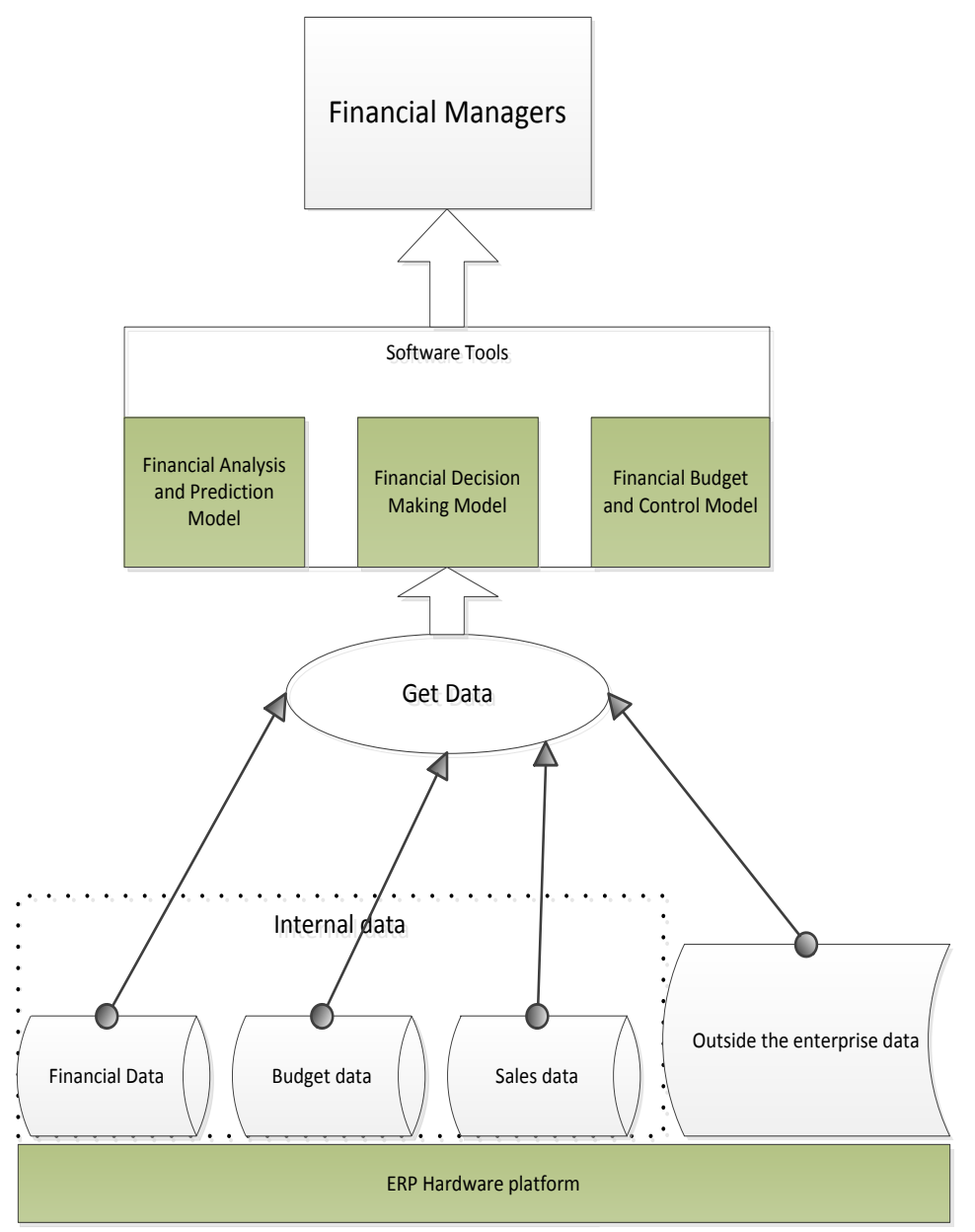

Fig.4: Application Environment Relations Financial Management Information System

ERP-based financial management system environment has the following characteristics:

High level of integration. Under the ERP environment, data collection and access to financial management systems are highly integrated. In highly integrated system, the data in the system in favor of the prediction decision makers and also more timely access to information. Under the ERP environment, financial management system not only to achieve financial and business collaboration, namely business and data processing occurs in real-time synchronization of protection of information, but also to achieve a variety of management information flowing in and out of highspeed Internet freedom, so it is easy to achieve scientific decision.

Dynamic information services. Financial systems and business systems are highly collaborative, market demand is changing financial management ERP environment as a starting point for rapid financial budget, provides dynamic financial information, support dynamic financial management.

Comprehensive information services. ERP to achieve the centralized management of corporate resources, all of the data belonging to the business activities are stored in a central database, so that the data source financial management system becomes more convenient, more comprehensive financial management information.

Strengthening financial decision support functions. The central role of financial planning is to analyze differences in budget and actual implementation, and to help make the necessary adjustments. Under the ERP environment, the use of accounting information, financial resources and financial analysis module can be budgeting and forecasting, modeling and analysis of the data in real time, so that financial decisions more scientific management.

\section{Systems analysis summary}

Financial Management System based on ERP environment and traditional management systems have made great progress, specifically in about one aspect: 
Financial data is based on the nature of the business occurred unified organization, preparation of consolidated financial statements in favor of the system, breaking the traditional financial management system set up multi-level details of subjects ideas.

Compared with the traditional system the most important feature of ERP system is that business and financial management are unified, therefore, information collection is very extensive and data for each sector is shared, consistency of the data can eliminate redundant data and duplication.

ERP system is a powerful information system, the majority of business data is stored in an original way, and to facilitate the combination of query.

\section{Conclusions}

This paper analyzes the status quo of corporate financial management, combined with information management system model for ERP-based corporate financial information management system has been specifically analyzed, through system design and system analysis, corporate financial information obtained under management ERP system the difference between the system and the traditional management system for corporate financial information management provides some suggestions and references, has some practical significance. Due to time constraints, this article, there are still some deficiencies that need to be perfect in subsequent work.

\section{References}

[1] Li Yongdong. The Application Research on ERP System in Enterprise Accounting and Financial Management [J].VALUEENGINEERING, 2010, 29(20):39-40.DOI:10.3969/j.issn.10064311.2010.20.024.

[2] Zeng Jianshan, Chen Zhao yang. Function and Application of Financial Information System Based on ERP [J].VALUEENGINEERING, 2007, 26 11):98-101.DOI:10.3969/j.issn.10064311.2007.11.035.

[3] Wang Zeshan, the Financial Information System Problem Discussed in This Paper [J]. FRIENDS OF ACCOUNTING, 2010, (21):98-100.DOI:10.3969/J.issn.1004-5937. 2010. 21.043.

[4] Zheng Tingting. ERP Financial Information System Risk Analysis [J]. JOURNAL OF CHIFENG UNIMERSITY, 2010, 26(5):47-49.DOI:10.3969 /j.issn.1673-260X.2010.05.021.

[5] Wu Beihao. Under the ERP System of Enterprise Financial Information System Building [J]. Times finance, 2012, (6):62-63.

[6] Xu Fei. Hospital Financial Information System Design Based on ERP [J]. FOREIGN INVESTMENT IN CHINA, 2009, (5): 85-86. DOI: 10.3969 /j.issn.1004-8146-B. 2009.05.059. 